\title{
Sudden sensorineural hearing loss in a multiple sclerosis case
}

\author{
Muhammet Tekin ${ }^{1}$, Gul Ozbilen Acar' ${ }^{1}$, Osman Halit Cam², Fatih Mehmet Hanege ${ }^{3}$ \\ ${ }^{1}$ Department of Otorhinolaryngology, Istanbul Medeniyet University Goztepe Training and Research Hospital, Istanbul, Turkey; \\ 2Department of Otorhinolaryngology, Delta Hospital, Istanbul, Turkey; \\ ${ }^{3}$ Department of Otorhinolaryngology, Op. Dr. Ergun Ozdemir Görele Devlet Hastanesi, Giresun, Turkey
}

\begin{abstract}
Multiple sclerosis (MS) is the most common demyelinating disease of the central nervous system. MS involves different regions of the central nervous system in different periods, and causes demyelination. MS is a neuromotor disorder which progresses with remissions and relapses. Symptoms of MS may regress completely or heal after the relapses leaving sequelae. Sudden sensorinerural hearing loss (SSHL) is hearing loss of $30 \mathrm{~dB}$ or more over at least three contiguous audiometric frequencies that develops over a period of a few hours to 3 days. In 4-10 $\%$ of the MS patients, sensorineural hearing loss occurs between relapses or remissions. In this case, audiotory brainstem response (ABR) test is the most appropriate test for the diagnosis of sensorineural hearing loss in MS patients. In this article, we will discuss a patient diagnosed as MS who presented with sudden sensorineural hearing loss during the remission of the disease.
\end{abstract}

Key words: Multiple sclerosis, sudden sensorineural hearing loss.

$\mathrm{M}$ ultiple sclerosis (MS) is the most common demyelinating disease of the central nervous system. MS is a neuromotor disorder which progresses with remissions and relapsing periods. More than 2 million patients in the world are estimated to be diagnosed with multiple sclerosis [1]. Multiple sclerosis is classified in four different groups by Multiple Sclerosis Association of America in 1996 as follows: 1- Relapsing remitting, 2- Secondary progressive, 3- Primary progressive, 4- Progressive relapsing [2]. Symptoms of MS plaques may regress completely or heal by leaving a sequellae.

Symptomatology of MS may be very variable. Hypoesthesia, paresthesia, muscle weakness, myoclonus, muscle spasms, ataxia, dysarthria, dysphagia, acute and chronic pain, and visual symptoms are common for the disease [3]. These symptoms usually show variations depending on the localization of demyelinated plaques in the central nervous system. In the presence of demyelinated plaques affecting pons or pontocerebellar area, sudden hearing loss may be encountered. In this article, we discuss

Received: June 22, 2014 Accepted: September 26, 2014 Online: December 08, 2014

Correspondence: Fatih Mehmet HANEGE. Trabzon Giresun Yolu, Bozcaali Mahallesi, Mehmet Burnu, Gorele, 28800 Giresun, Turkey.

Tel: +90 454 - 5131138 e-mail: hanege@hotmail.com

(c) Copyright 2014 by Istanbul Northern Anatolian Association of Public Hospitals - Available online at www.kuzeyklinikleri.com 
an MS case which was diagnosed based on symptoms of sudden hearing loss when the patient was in the remission phase of the disease.

\section{CASE REPORT}

A 30-year-old female patient admitted to our hospital with sudden hearing loss and tinnitus in the right ear. These complaints had been continuing for three days. The patient was diagnosed as MS 3.5 years ago. Her medical history also included lumbar discopathy. She'd been using beta interferon at a dose of $0.3 \mathrm{mg}$ on alternate days for the treatment of MS for the last 3.5 years. Physical examination of the patient demonstrated intact bilateral tympanic membranes, Weber test was lateralized to the left ear, Rinne test was positive $(+/+)$ in the left, and false negative $(+/-)$ in the right ear. Pure tone audiogram was performed on the patient with the initial diagnosis of sudden hearing loss (Figure 1). The final diagnosis was total hearing loss in the right ear (air conduction/bone conduction: 113/67 dB). The hearing acuity of the left ear was determined to be in normal hearing range (air conduction/bone conduction: $18 / 12 \mathrm{~dB}$ ).

After the patient was admitted to our clinic, routine laboratory tests were run. In the laboratory tests; there were no abnormal findings except WBC; $12.7 \times 10^{3} / \mathrm{mm}^{3}$, triglycerides; $34 \mathrm{mg} / \mathrm{dL}, \mathrm{CK}-\mathrm{MB}$; $25 \mathrm{U} / \mathrm{l}, \mathrm{UIBC} ; 366 \mathrm{ug} / \mathrm{dL}$. Contrast-enhanced cranial magnetic resonance imaging (MRI) and neurology consultation were ordered for the patient. As a result of the consultation, there was no active plaque on the cranial MRI at this time. Accordingly, a new MS attack was not anticipated. To investigate vascular, connective tissue pathologies or infectious etiologies, the results of new laboratory tests were as follows: rheumatoid factor $<20$, anti-nuclear antibody; negative (-), anti-phospholipid Ig G; negative (-), anti-phospholipid IgM; negative (-). Levels of protein C, protein S, Von Willebrant Factor antigen were in their normal ranges. In Elisa tests, levels of anti-toxoplasma Ig $\mathrm{M}$, anti-CMV Ig $\mathrm{M}$, EBV VCA Ig M, anti-HSV-1 Ig M, anti-HSV-2 Ig M, VDRL-RPR, anti-ds DNA were within their normal ranges. In the light of these findings, classical parenteral treatment protocol of sudden sensorineural hearing loss was prescribed as prednisolone $\mathrm{kg} / 1 \mathrm{mg} /$ day with tapering dose, ranitidine $50 \mathrm{mg} /$

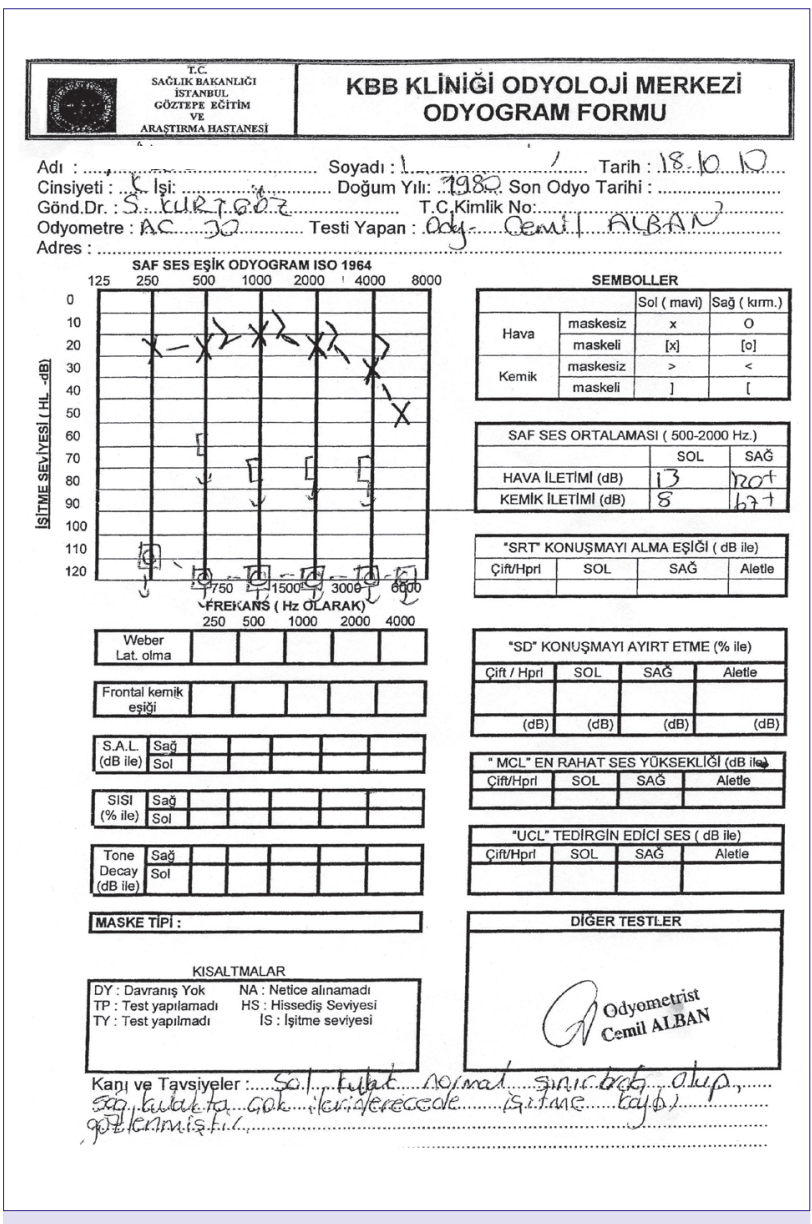

FIGURE 1. The audiogram reveals sudden senseurineural hearing loss on the right ear.

day, pentoxifylline $900 \mathrm{mg} /$ day, low-molecularweight heparin $0.6 \mathrm{ml} /$ day, acyclovir $2 \mathrm{~g} /$ day. Also hyperbaric oxygen therapy was administrated to the patient for 10 days at doses of $2.5 \mathrm{ATA} /$ day.

Pure tone audiogram was performed totally 3 times during hospitalization period. In spite of all our medical treatments, there was no sign of hearing improvement either audiologically or clinically. The patient was discharged with oral treatment and followed up in our outpatient clinic. At the end of our treatment, audiologic examinations were performed. In November, one month after the onset of the disease, there was not any hearing improvement as detected on her pure tone audiogram (Figure 2). Three months later spontaneous recovery was observed on her pure tone audiogram Air / bone conduction $13 / 7 \mathrm{~dB}, 30 / 27 \mathrm{~dB}$ were reported for the left, and the right ear, respectively (Figure 3). Ad- 


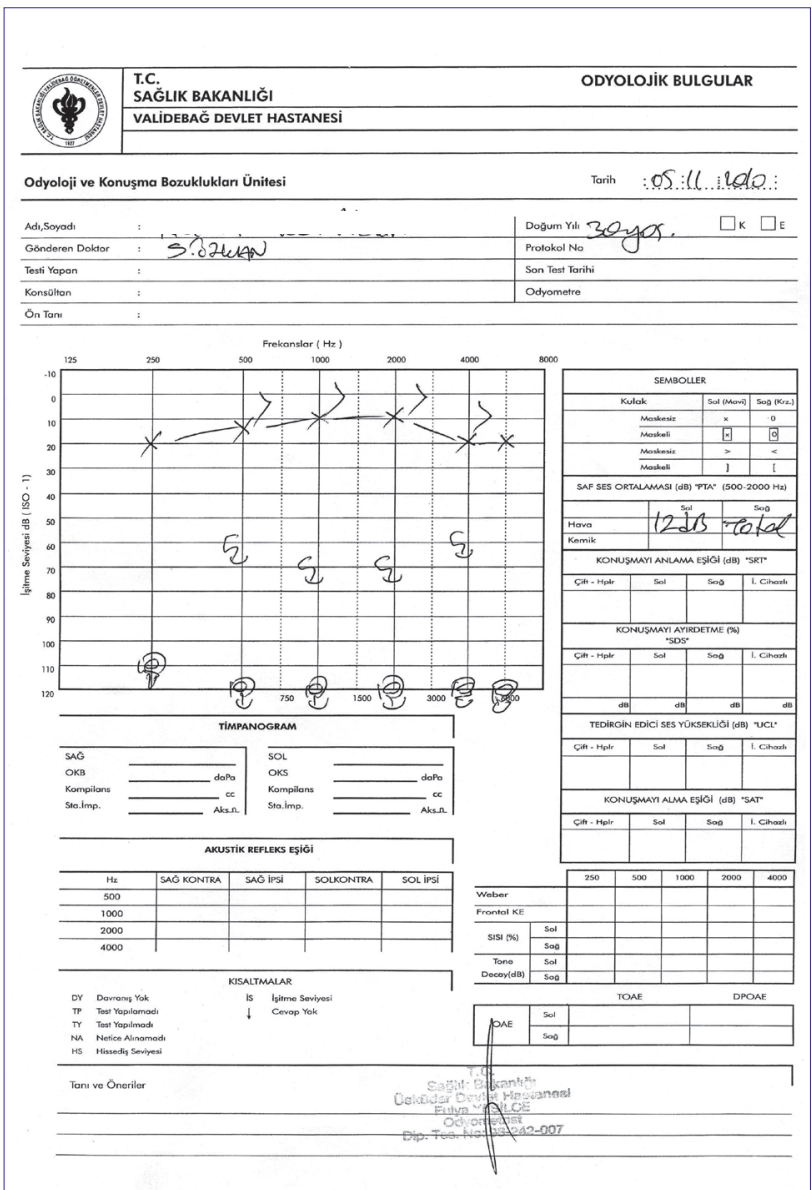

FIGURE 2. The audiogram after the treatment shows no improvement.

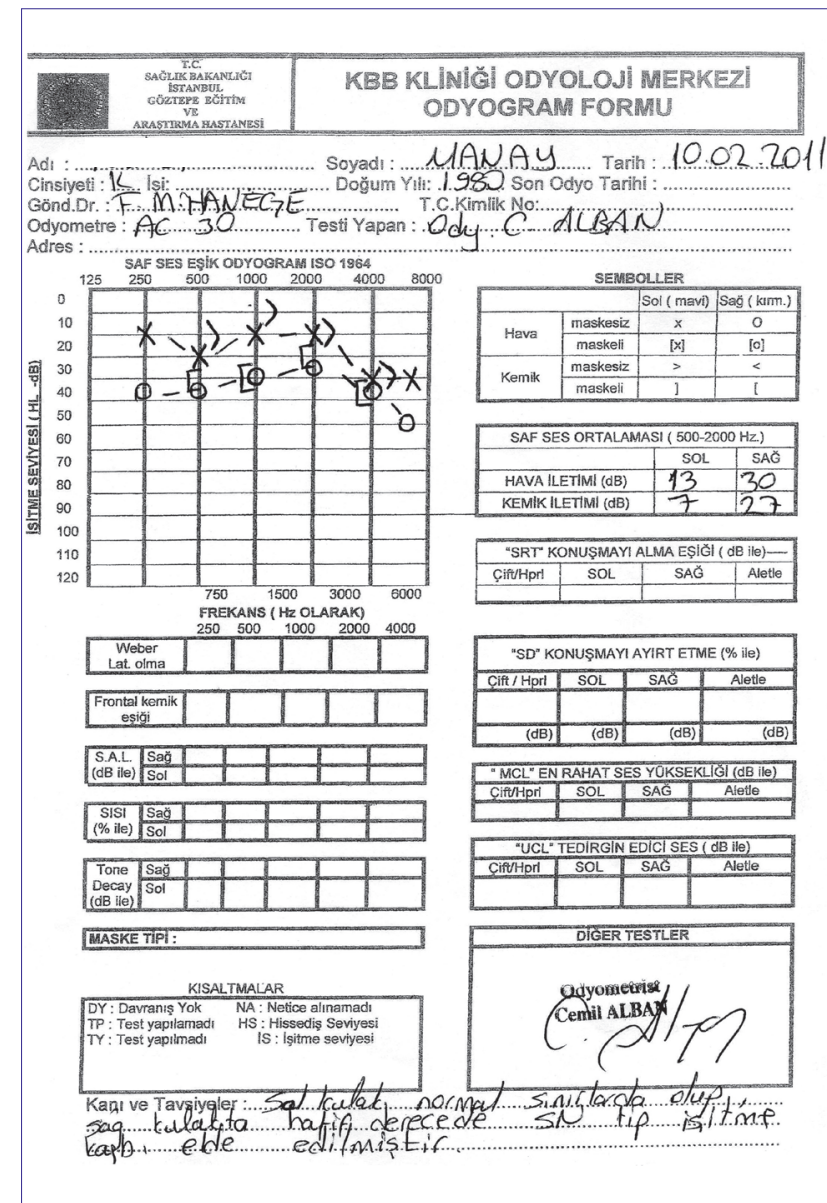

FIGURE 3. The audiogram shows spontaneous recovery of the right ear.

TABLE 1. The elongation in third and fifth wave latencies and III $-\mathrm{V}$ interpeak latencies as well

\section{BAER}

Protocol/Run

$\begin{array}{cc}\text { Aud.Stim } & \text { I } \\ \mathrm{dB} & \mathrm{ms}\end{array}$

$\begin{array}{ll}\text { III } & \mathrm{V} \\ \mathrm{ms} & \mathrm{ms}\end{array}$

I-V

IIIII
$\mathrm{ms}$

5.48
5.54
5.54
5.40

3.76

2.20

3.78

2.06

1.56

1.72

3.92

2.28

1.64

3.94

2.38

1.56

4.04

2.08

1.96

4.04

2.08

1.96

1.84

1.88

$\begin{array}{llll}5.94 & 3.84 & 2.00 & 1.84 \\ 5.96 & 4.04 & 2.16 & 1.88\end{array}$

6.00

6.00

5.96

$\begin{array}{ll}80 \mathrm{nHL} & 1.96 \\ 80 \mathrm{nHL} & 1.96 \\ 70 \mathrm{nHL} & 2.10 \\ 70 \mathrm{nHL} & 1.92\end{array}$

4.04

2.16

\begin{tabular}{cc}
$\begin{array}{c}\text { Rep.Rate } \\
\mathrm{ms}\end{array}$ & Type \\
& $\mathrm{pps}$ \\
\hline
\end{tabular}

Type
pps 
ditionally, auditory brain response (ABR) test was performed. Prolongation of the absolute latency of 3. and 5. waves, and interpeak latency of 3.-5. waves were found in $A B R$ of the right ear (Table 1 ). Depending on these findings, the patient's sudden hearing loss of the right ear might be related to MS disease.

\section{DISCUSSION}

Sudden hearing loss (SHL) is a hearing loss of 30 $\mathrm{dB}$ or more, over at least three contiguous audiometric frequencies, that develops over a period of a few hours to 3 days $[4,5,6,7,8,9]$. The etiology of the disease is not certain, but autoimmune vascular malformations, thrombotic, and central nervous system diseases are among the main reasons $[4,5]$. MS is a demyelinating disease of the central nervous system that involves the white substance. The disease often has periods of remissions and relapses. Its etiopathogenesis is not totally understood. In genetically inclined patients, viral infection may trigger the autoimmunity that causes the disease. Demyelinated plaques typically effect the periventricular white substance of the central nervous system. Rarely cerebellum, brain stem and spinal cord can be effected by MS. As a result of autoimmunity, intravascular $T$ cells attack the myelin sheath, and nerve fibers, then it starts as an inflammatory process. On the other hand, neural regeneration begins in order to stop the damage at a minimum level. In 4-10\% of MS patients, sensorineural hearing loss occurs during periods of relapse or remission [5, 6]. Detection of brain lesions of MS in MRI, can provide evidence concerning the dissemination of MS lesions in space and time. Therefore a diagnosis of MS should be guided by the defined criteria of MRI for this abnormality [10].

Hearing loss in MS disease may be due to plaques which are placed on brain stem, any area of entrance of cochlear nerve into the brain stem, and auditory cortex $[6,7]$. In this situation, auditory brainstem response (ABR) test is the most appropriate test for the diagnosis of sensorineural hearing loss in MS patients. Typical findings are the elongations in all waves' absolute latencies except I. wave. Also, elongations in interpeak latencies of IIII, III-V waves or changes in the morphology and amplitudes of III and V wave's may be observed [7,
8]. In the right ear ABR of our patient, we observed elongation in absolute latencies of waves III and V, as well as III-V waves' interpeak latencies.

If sudden hearing loss is related with MS, it usually recovers without sequellae. In a retrospective study of Hellman and his colleagues, 253 MS patients with sensorineural hearing loss were scanned, and sudden hearing loss was diagnosed in 11 of them. Nine of these patients recovered without audiological deficits $[8,9]$. In our patient, sudden hearing loss recovered with a mild sensorineural hearing loss, and no recurrence was observed in one year follow-up.

In conclusion, whenever sudden hearing loss is diagnosed in a patient, physicians should request cranial imaging to differentiate for cranial pathologies such as MS. Sudden hearing loss can be the first symptom of MS or may indicate relapse of the disease.

Conflict of Interest: No conflict of interest was declared by the authors.

Financial Disclosure: The authors declared that this study has received no financial support.

\section{REFERENCES}

1. Peterson JW, Trapp BD. Neuropathobiology of multiple sclerosis. Neurol Clin 2005;23:107-29. CrossRef

2. Tiong TS. Prognostic indicators of management of sudden sensorineural hearing loss in an Asian hospital. Singapore Med J 2007;48:45-9.

3. Lublin FD, Reingold SC. Defining the clinical course of multiple sclerosis: results of an international survey. National Multiple Sclerosis Society (USA) Advisory Committee on Clinical Trials of New Agents in Multiple Sclerosis. Neurology 1996;46:907-11.

4. Compston A, Coles A. Multiple sclerosis. Lancet 2008;372:150217. CrossRef

5. Conlin AE, Parnes LS. Treatment of sudden sensorineural hearing loss: I. A systematic review. Arch Otolaryngol Head Neck Surg 2007;133:573-81. CrossRef

6. Peyvandi A, Naghibzadeh B, Ahmady Roozbahany N. Neurootologic manifestations of multiple sclerosis. Arch Iran Med 2010;13:188-92.

7. Oh YM, Oh DH, Jeong SH, Koo JW, Kim JS. Sequential bilateral hearing loss in multiple sclerosis. Ann Otol Rhinol Laryngol 2008;117:186-91.

8. Protti-Patterson E, Young ML. The use of subjective and objective audiologic test procedures in the diagnosis of multiple sclerosis. Otolaryngol Clin North Am 1985;18:241-55.

9. Hellmann MA, Steiner I, Mosberg-Galili R. Sudden sensori- 
neural hearing loss in multiple sclerosis: clinical course and possible pathogenesis. Acta Neurol Scand 2011;124:245-9. CrossRef 10. McDonald WI, Compston A, Edan G, Goodkin D, Hartung
HP, Lublin FD, et al. Recommended diagnostic criteria for multiple sclerosis: guidelines from the International Panel on the diagnosis of multiple sclerosis. Ann Neurol 2001;50:121-7. CrossRef 